\title{
Factor VII deficiency in systemic primary amyloidosis: A rare case
}

\author{
Fadime Ersoy Dursun*1, Erdal Akyar ${ }^{2}$, Gokhan Uygun ${ }^{2}$, Zafer Baslar ${ }^{3}$, Bengu Cobanoglu ${ }^{4}$ \\ ${ }^{1}$ Department of Hematology, Istanbul Medeniyet University Goztepe Training and Research Hospital, Istanbul, Turkey \\ ${ }^{2}$ Department of Internal Medicine, Istanbul Medeniyet University Goztepe Training and Research Hospital, Istanbul, Turkey \\ ${ }^{3}$ Department of Hematology, Istanbul University Cerrahpasa Medical Faculty, Istanbul, Turkey \\ ${ }^{4}$ Department of Pathology, Istanbul Medeniyet University Goztepe Training and Research Hospital, Istanbul, Turkey
}

Received: October 22, 2018

DOI: $10.5430 /$ crim.v5n4p 28
Accepted: November 30, 2018 Online Published: December 10, 2018

URL: https://doi.org/10.5430/crim.v5n4p28

\begin{abstract}
Introduction: Isolated and combined factor deficiencies are known to occur in systemic primary amyloidosis. The most common factor deficiency known in these cases is isolated factor X deficiency. Other factor deficiencies are relatively less frequent. Isolated factor VII deficiency occurs very rarely in cases of systemic primary amyloidosis.

Case report: A 58-year-old male patient previously presenting to another health center with complaints of generalized edema, fatigue, and itching had proteinuria and then he was diagnosed with systemic primary amyloidosis after the renal biopsy for proteinuria etiology. The patient's laboratory tests showed prolongation of prothrombin time and factor VII deficiency. The patient responded well to the treatment for primary amyloidosis and factor VII deficiency.

Discussion: In cases of systemic primary amyloidosis, if the etiology of prolonged prothrombin time involves no liver disease, warfarin use, or malabsorption, physicians should always keep in mind rare factor deficiencies such as factor VII deficiency, along with common factor deficiencies.
\end{abstract}

Key Words: Systemic primary amyloidosis, Isolated factor VII deficiency

\section{INTRODUCTION}

Amyloidosis refers to a group of rarely seen serious diseases caused by accumulation of an abnormal protein called "amyloid" in human tissues and organs. Systemic amyloidosis types are categorized as primary, secondary, or familial (inherited). Primary amyloidosis (AL) is the most prevalent type of systemic amyloidosis. In secondary amyloidosis (AA), the inflammatory protein is derived by serum amyloid A. ${ }^{[1]}$

Coagulation factor deficiencies are common in cases of systemic primary amyloidosis. ${ }^{[2]}$ Combined factor deficiencies like factor IX-factor X or factor VII-factor X are rarely reported in these patients, while isolated factor II, factor V, and factor IX deficiencies are often occurrences. ${ }^{[3-5]}$ Isolated factor VII deficiency is a quite rare condition in amyloidosis, and just one case has so far been reported in the literature. ${ }^{[6]}$ Conditions associated with rare clotting disorders, such as factor VII deficiency, in these patients, are often overlooked, or go unrecognized. Hereditary factor VII deficiency is categorized as type 1 or type 2 based on the finding that whether factor VII antigen exists in the plasma. Type 1 deficiencies are caused by a reduction in biosynthesis or acceleration in

\footnotetext{
*Correspondence: Fadime Ersoy Dursun; Email: drfadimeersoy@yahoo.com.tr; Address: Department of Hematology, Istanbul Medeniyet University Goztepe Training and Research Hospital, Istanbul, Turkey.
} 
clarify; Type 2 abnormalities, on the other hand, represent a dysfunctional molecule. Today, classification depending on patient's clinical history including age and presentation type of the patient instead of factor VII activity levels has been shown to be a more valuable tool in determining future bleeding risks. ${ }^{[5,6]}$ Here we report a rare case of isolated factor VII deficiency, detected while the patient was tested for prolongation of prothrombin time (PT) associated with systemic primary amyloidosis. We obtained a written informed consent from the patient for this case report.

\section{CASE REPORT}

A 58-year-old male patient previously presenting to another health center with complaints of generalized edema, fatigue, and itching had proteinuria and then he was diagnosed with systemic primary amyloidosis after the renal biopsy for proteinuria etiology. The patient was referred to our department and then hospitalized for further examination and treatment. The patient reported no history of chronic diseases in family, and the coagulation test results were normal and he had no history of bleeding disorders.

The general condition of the patient was moderate-to-good; his vital findings were stable, and he was fully conscious, oriented, cooperative, with pale skin and generalized edema, as well as pretibial pitting (+++) edema (see Figure 1a). Examinations of the head and neck, eyes, ears, nose, throat, respiratory, cardiovascular, and genitourinary systems were normal. In his examination of the gastrointestinal system, there was abdominal distention and tenderness, as well as acid in the area extending from the lower abdomen to the umbilical region (see Figure 1b). The bowel sounds were natural, with no rebound, guarding, hepatomegaly and splenomegaly, and other system examinations were normal.

The results of laboratory tests and normal values are shown in Table 1. His leukocyte count was $8,300 / \mathrm{mm}^{3}$, absolute neutrophil count $4,870 / \mathrm{mm}^{3}$, hemoglobin $10.4 \mathrm{gr} / \mathrm{dl}$, hematocrit $32 \%$, platelets $222,000 / \mathrm{mm}^{3}$, PT $17.9 \mathrm{sec}$, active partial thromboplastin time $34 \mathrm{sec}$, and INR 1.48. Biochemical analyses showed an urea level of $45 \mathrm{mg} / \mathrm{dl}$, creatinine $0.73 \mathrm{mg} / \mathrm{dl}$, total protein $4.5 \mathrm{~g} / \mathrm{dl}$, albumin $1.8 \mathrm{~g} / \mathrm{dl}$, aspartate aminotransferase $22 \mathrm{IU} / \mathrm{L}$, alanine aminotransferase 6 IU/L, gamma glutamyl transferase 143 IU/L, alkaline phosphatase $266 \mathrm{IU} / \mathrm{L}$, lactate dehydrogenase $193 \mathrm{IU} / \mathrm{L}$, glucose $98 \mathrm{mg} / \mathrm{dl}$, total cholesterol $267 \mathrm{mg} / \mathrm{dl}$, triglyceride $193 \mathrm{mg} / \mathrm{dl}$, LDL-cholesterol $201 \mathrm{mg} / \mathrm{dl}$, HDL-cholesterol $27 \mathrm{mg} / \mathrm{dl}$, calcium $7.2 \mathrm{mg} / \mathrm{dl}$, phosphorus $4.2 \mathrm{mg} / \mathrm{dl}$, and $\beta 2$-microglobulin $6,421 \mathrm{ng} / \mathrm{ml}$. 24 hour urine analysis of the patient revealed proteinuria levels of $6,000 \mathrm{mg} / 24 \mathrm{~h}$, glomerular filtration rate $104 \mathrm{ml} / \mathrm{min} / 1.73 \mathrm{~m}^{2}$. Besides, sedimentation was 77 $\mathrm{mm} / \mathrm{s}$, c-reactive protein $0.45 \mathrm{mg} / \mathrm{dl}$, and brain natriuretic

Published by Sciedu Press peptide $360 \mathrm{pg} / \mathrm{ml}$. There was no monoclonal band on serum and urine immunofluorescence electrophoresis. Serum protein electrophoresis showed no $\mathrm{M}$ protein band. The initial primary amyloidosis diagnosis was supported by the bone marrow biopsy performed in our unit, and the level of plasma cells in the bone marrow was found to be less than $5 \%$ and polyclonal.

The patient's full abdominal ultrasound showed a liver craniocaudal diameter of $186 \mathrm{~mm}$ and enlarged long axis of spleen measuring $168 \mathrm{~mm}$. The ultrasound imaging also showed generalized free fluid in the abdomen. The positron emission tomography/computed tomography (CT scan) found no pathologic radiopharmaceutical F-18 fluorodeoxyglucose involvement or lytic bone lesion on direct CT images. In cardiac magnetic resonance imaging, there was a slight concentric hypertrophic appearance in the left ventricle; interventricular septum thickness in diastole was $14 \mathrm{~mm}$ and slightly above the physiological limits, and minimal effusion in the pericardial space.

The patient's elevated PT levels detected by initial tests did not improve with vitamin $\mathrm{K}$ treatment. No concomitant sepsis, renal insufficiency, disseminated intravascular coagulation or liver failure was detected. Mixing studies failed to confirm the presence of an inhibitor and therefore factor levels that could prolong the PT were examined (see Table 1). The Factor VII level was found to be $46 \%$ and Factor VII antigen was 52\%, so isolated Factor VII deficiency was considered because these levels were below normal values. Other factor levels were normal (see Table 1). In the bone marrow biopsy specimens, eosinophilic amorphous proteinaceous deposits were observed on the vein walls and histochemical and immunohistochemical staining confirmed amyloid presence (see Figure 2). There was no bleeding complication during renal and bone marrow biopsy of the patient. Upon these findings, we decided that the patient had factor VII deficiency accompanying nephrotic syndrome and systemic primary amyloidosis. He was treated with vitamin K regimen for prolonged levels of PT, but no improvement was observed. A combination regimen of VCD (Cyclophosphamide, Bortezomib, Dexamethasone) was initiated for primary amyloidosis in the patient, as he was considered to be in the moderate risk group based on his glomerular filtration rate and proteinuria. ${ }^{[2,7]}$ After three cycles of treatment, the general condition and renal functions of the patient returned to normal, with improved edema, acid and acidosis (see Figure 1c, d). A significant reduction was achieved in the proteinuria of the patient, and factor VII level (178\%) and coagulation test results [PT $14.9 \mathrm{sec}$ (11.5-15.5), INR 1.2 (0.8-1.25), activated partial thromboplastin time $30 \mathrm{sec}$ (25.6-35.2)] returned to normal values. 


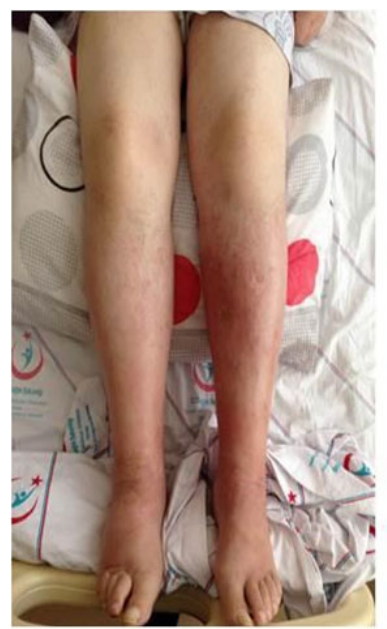

a

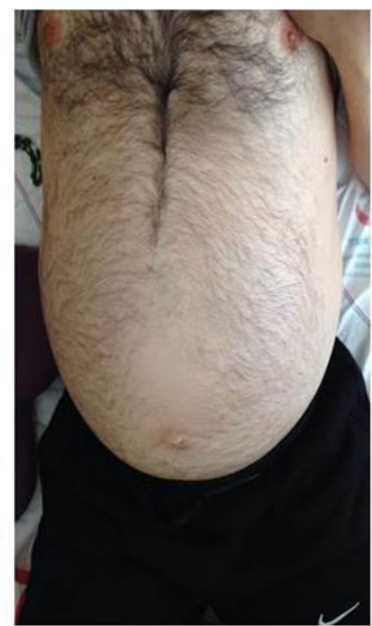

b

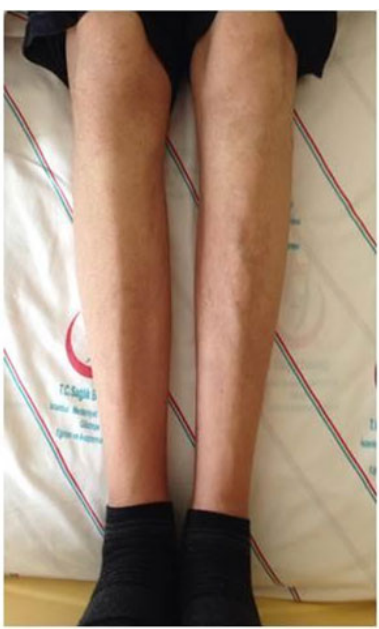

C

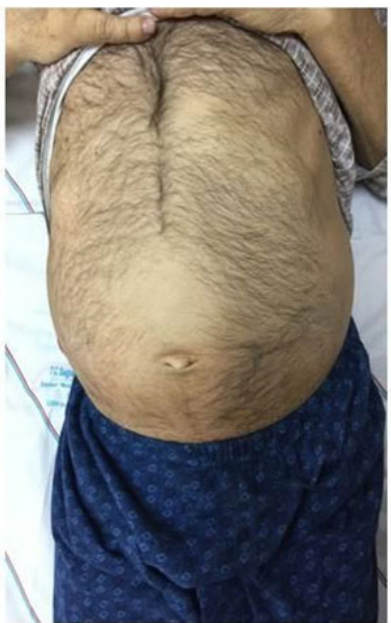

d

Figure 1. Ascites and pretibial edema of the patient before and after treatment. Pretibial edema (a) and ascites (b) finding before treatment, Pretibial edema (c) and ascites (d) finding after treatment.

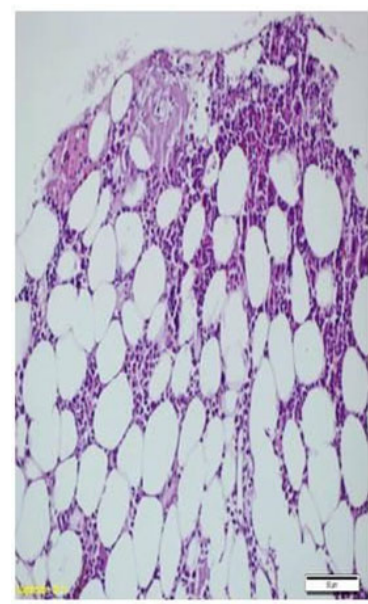

a

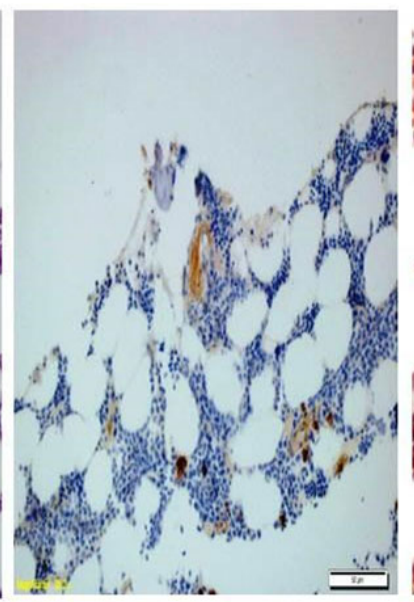

b

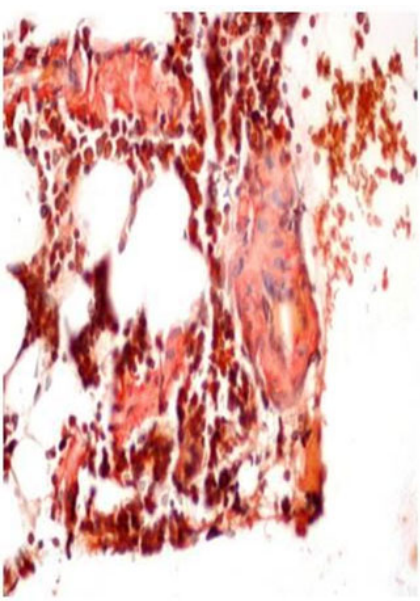

C

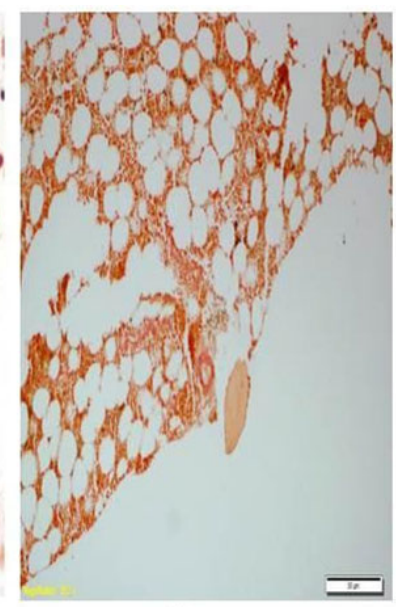

d

Figure 2. Bone marrow biospy specimen; a. The accumulation of proteinaceous material in the wall of vascular structures $\mathrm{HE} \times 200$, b. immunohistochemical Amyloid A staining AA protein $\times 400$, c. Histochemically, Congo red staining $\times 400$, d. Histochemically Permanganant Congo $\times 400$.

\section{Discussion}

Acquired factor $\mathrm{X}$ deficiency in patients diagnosed with amyloidosis is well defined; however, cases of acquired factor VII deficiency are quite rare in the literature. Hemorrhage is known to be a typical symptom of systemic primary amyloidosis and can be a serious problem. Approximately one-third of the patients exhibit bleeding symptoms and about half of the patients show abnormal clotting findings. ${ }^{[8]}$ Although the most common symptom of hemorrhage is purpura because of increased vascular fragility resulting from the deposition of endothelial amyloid material, life-threatening bleeding following liver or kidney biopsy is a well-established find- ing, with another characteristic finding of periorbital purpura ("raccoon eyes"). ${ }^{[8]}$ Previous works in the literature have reported that clotting factors regulating blood clot formation are amyloid-dependent and certain improvements were achieved in haemostasis once the spleen had been removed because it was severely infiltrated by amyloid material. ${ }^{[9]}$ Most of the coagulation abnormalities have been explained by poor fibrin polymerization or a decrease in factor $\mathrm{X}$ activity. However, the literature includes several studies reporting that coagulopathy was reversed following cytotoxic chemotherapy. ${ }^{[10]}$ Even though our patient showed no significant bleeding symptoms, we detected that he had pro- 
longed PT. Based on this finding, we managed to diagnose the patient with factor VII deficiency, which is a very rare occurence in the literature.

Table 1. Laboratory findings of patient

\begin{tabular}{|c|c|c|}
\hline Parameters (unit) & Results & Reference intervals \\
\hline Leukocyte $\left(\mathrm{mm}^{3}\right)$ & 8,300 & $4,000-10,000$ \\
\hline ANC $\left(\mathrm{mm}^{3}\right)$ & 4,870 & $1,400-6,500$ \\
\hline Hemoglobin (gr/dl) & 10.4 & $13-17$ \\
\hline Hematocrit (\%) & 32 & $40-54$ \\
\hline Platelets $\left(\mathrm{mm}^{3}\right)$ & 222,000 & $150,000-500,000$ \\
\hline Protrombin time (sec) & 17.9 & $11.5-15.5$ \\
\hline aPTT (sec) & 34 & 25.6-35.2 \\
\hline INR & 1.48 & $0.8-1.25$ \\
\hline Urea (mg/dl) & 45 & $18-55$ \\
\hline Creatinine (mg/dl) & 0.73 & $0.72-1.25$ \\
\hline $\operatorname{GFR}\left(\mathrm{ml} / \mathrm{min} / 1.73 \mathrm{~m}^{2}\right)$ & 104 & $>90$ \\
\hline Total proteine (gr/dl) & 4.5 & $6.4-8.3$ \\
\hline Albumine (gr/dl) & 1.8 & $3.5-5.2$ \\
\hline AST (IU/L) & 22 & $<37$ \\
\hline ALT (IU/L) & 6 & $<42$ \\
\hline GGT (IU/L) & 143 & $<64$ \\
\hline ALP (IU/L) & 266 & $<150$ \\
\hline LDH (IU/L) & 193 & $125-220$ \\
\hline Glucose (mg/dl) & 98 & $70-105$ \\
\hline Total cholesterol (mg/dl) & 267 & $<200$ \\
\hline Triglycerides (mg/dl) & 193 & $<150$ \\
\hline LDL-cholesterol (mg/dl) & 201 & $<130$ \\
\hline HDL-cholesterol (mg/dl) & 27 & $35-65$ \\
\hline Calcium (mg/dl) & 7.2 & 8.4-10.2 \\
\hline Phosphorus (mg/dl) & 4.2 & 2.3-4.7 \\
\hline Sedimentation $(\mathrm{mm} / \mathrm{h})$ & 77 & $<15$ \\
\hline CRP (mg/dl) & 0.45 & $0-05$ \\
\hline Brain NP (pg/dl) & 360 & $0-100$ \\
\hline$\beta_{2}$-microglobuline (ng/ml) & 6,421 & $<2,500$ \\
\hline Factor II (\%) & 110 & $50-150$ \\
\hline Factor V (\%) & 84.6 & “ \\
\hline Factor VII (\%) & 46 & “ \\
\hline Factor IX (\%) & 70.4 & “ \\
\hline Factor X (\%) & 91 & “ \\
\hline Factor XI (\%) & 64 & “ \\
\hline Factor XII (\%) & 77.7 & “ \\
\hline vWF (\%) & 199.5 & “ \\
\hline vWF ristocetin cofactor (\%) & 184.4 & “ \\
\hline Factor VII antigen (\%) & 52 & $70-120$ \\
\hline $\begin{array}{l}24 \text { hours urine proteine } \\
\text { (mg/24h) }\end{array}$ & 6,000 & $0-150$ \\
\hline
\end{tabular}

Note. ANC: Absolute neutrophil count, aPTT: Activated partial thromboplastin time, INR: international normalised ratio, AST: Aspartate amino transferase, ALT: Alanine amino transferase, GGT: gamma glutamyl transferase, LDH: lactate dehydrogenase, CRP: C-reactive protein, vWF: von willebrand factor

Factor VII deficiency may be inherited or acquired. Inherited factor VII deficiency is known to be a rare but serious au- tosomal recessive bleeding condition. Blood clotting factor VII is a coagulation factor dependent on vitamin $\mathrm{K}$ and is synthesized in the liver. It is usually found in human plasma at low concentrations $(0.5 \mathrm{mcg} / \mathrm{ml})$ with a relatively short half-life of 3-4 hours in the circulation. Factor VII is often found in the shape of an inactive single-chain zymogen. Nevertheless, it is present in the circulation at the rate of $1 \%$ in an activated form (FVIIa). The activation of Factor VII initiates a series of extracellular coagulation events. ${ }^{[11,12]}$ A defect such as Factor VII deficiency could occur with mild-to-moderate severity and may present itself with a minor prolongation in the PT. If physicians do not run certain coagulation factor tests to further investigation of isolated PT prolongation, they may not diagnose the condition accurately. We detected isolated factor VII deficiency in a patient recently diagnosed with systemic primary amyloidosis who had mild-to-moderate, isolated PT prolongation and no bleeding symptom. ${ }^{[13-15]}$ In the relevant literature, there is no study reporting any case of isolated factor VII deficiency in systemic primary amyloidosis, except for the one reported by Uematsu et al. ${ }^{[5]}$

Current guidelines lack any evidence-based treatment options for hemorrhaging in amyloidosis patients. ${ }^{[7]}$ The evidence level for all the available recommendations is $4 \mathrm{C}$. In cases of bleeding, traditional supportive therapies should be administered, which may include the replacement of the deficient factor determined by clotting tests and platelet transfusion when thrombocytopenia is considered to contribute to bleeding based on platelet count. In addition, antifibrinolytic agents and local precautions can be utilized to achieve haemostasis. ${ }^{[2,7]}$ In light of these recommendations in the literature, we treated our patient with 3 cycles of VCD chemotherapy protocol. The patient's response to this treatment was good at the clinical and laboratory levels. The patient is still monitored in our clinic.

\section{Conclusion}

In conclusion, we decided to report this case in order for physicians to keep in mind the isolated factor VII deficiency in systemic primary amyloidosis patients. This case demonstrates the importance of meticulous evaluation of coagulation tests. Therefore, in cases of systemic primary amyloidosis with no liver disease, warfarin use, or malabsorption, physicians should always consider rare factor deficiencies such as factor VII deficiency, along with more common factors like Factor X, if the patient has prolonged PT.

\section{CONFLICTS OF INTEREST DisClOSURE}

The authors have declared no conflicts of interest. 


\section{REFERENCES}

[1] Kyle RA, Gertz MA. Primary systemic amyloidosis: clinical and laboratory features in 474 cases. Semin Hematol. 1995; 32: 45-59. PMid:7878478.

[2] Sucker C, Hetzel GR, Grabensee B, et al. Amyloidosis and bleeding: pathophysiology, diagnosis, and therapy. Am J Kidney Dis. 2006; 47 947-955. https://doi.org/10.1053/j.ajkd.2006.03.036

[3] Gatel A, Cacoub P, Piette JC. AL amyloidosis combined with acquired factor V deficiency. Ann Intern Med. 1998; 128: 604-605. https://doi.org/10.7326/0003-4819-128-7-199 804010-00030

[4] Mc Pherson RA, Onstad JW, Ugoretz RJ, et al. Coagulopathy in amyloidosis combined deficiency of factors IX and X. Am J Hematol. 1977; 3: 225-235.

[5] Uematsu M, Tsukaguchi M, Kinman K, et al. Case of factor VII deficiency with systemic amyloidosis having a unique clinical course such as splenic rupture. Nihon Naika Gakkai Zasshi. 1997; 86: 314-316. PMid:9139071. https://doi.org/10.2169/naika.86 .314

[6] Tuddenham EG, Pemberton S, Cooper DN. Inherited factor VII deficiency: genetics and molecular pathology. Thromb Haemost. 1995; 74: 313-321. https://doi .org/10.1055/s-0038-1642696

[7] Comenzo RL, Reece D, Palladini G, et al. Consensus guidelines for the conduct and reporting of clinical trials in systemic lightchainamyloidosis. Leukemia. 2012; 26: 2317-2325. PMid:22475872. https://doi.org/10.1038/leu.2012.100

[8] Mumford AD, O'Donnell J, Gillmore JD, et al. Bleeding symptoms and coagulation abnormalities in 337 patients with AL-amyloidosis.
British Journal of Haematology. 2000; 110: 454-460. https: //doi.org/10.1046/j.1365-2141.2000.02183.x

[9] Greipp PR, Kyle RA, Bowie EJ. Factor X deficiency in primary amyloidosis: resolution after splenectomy. N Engl J Med. 1979; 301: 1050-1051. PMid:492235. https : //doi .org/10.1056/NEJM19 7911083011907

[10] Camoriano JK, Greipp PR, Bayer GK, et al. Resolution of acquired factor $\mathrm{X}$ deficiency and amyloidosis with melphalan and prednisone therapy. N Engl J Med. 1987; 316: 1133-1135. PMid:3574359. https : //doi.org/10.1056/NEJM198704303161806

[11] Mandhyan R, Tiwari A, Cherian G. Congenital factor VII deficiency. Br J Anaesth. 2010; 104: 267-268. https ://doi .org/10.1093/ bja/aep389

[12] Acharya SS. Rare bleeding disorders in children: identification and primary care management. Pediatrics. 2013; 132: 882-892.

[13] Mariani G, Herrmann FH, Dolce A, et al. International Factor VII Deficiency Study Group. Clinical phenotypes and factor VII genotype in congenital factor VII deficiency. Thromb Haemost. 2005; 93: 481-487. PMid:15735798. https : //doi.org/10.1160/TH04-1 $0-0650$

[14] Mariani G, Herrmann FH, Schulman S, et al. International Factor VII Deficiency Study Group. Thrombosis in inherited factor VII deficiency. J Thromb Haemost. 2003; 1: 2153-2158.

[15] Girmann G, Wilker D, Stadie H, et al. Acquired isolated factor X deficiency associated with systemic amyloidosis. Case report and review of literature. Klin Wochenschr. 1980; 58: 859-862. PMid:7442086. https ://doi .org/10.1007/BF01476996 